\title{
Active and Reactive Power Strategies with Peak Current Limitation for Distributed Generation Inverters During Unbalanced Grid Faults
}

\author{
Antonio Camacho, Miguel Castilla, Jaume Miret, Member, IEEE, Angel Borrell and Luis García de Vicuña
}

\begin{abstract}
Distributed generation inverters have become a key element to improve grid efficiency and reliability, especially during grid faults. Under these severe perturbations, inverterbased power sources should accomplish low-voltage ride-through requirements in order to keep feeding the grid and support the grid voltage. Also, rated current can be required to better utilize reactive power provisions. This paper presents a reference generator capable to accomplish these two objectives: to keep the injected currents within safety values, and to compute the power references for a better utilization of the inverter power capacity. The reference generator is fully flexible since positive and negative active and reactive powers can be simultaneously injected to improve ride-through services. Selected experimental results are reported to evaluate the performance of the proposed reference generator under different control strategies.
\end{abstract}

Index Terms-Power control, low-voltage ride-through, voltage sag, grid fault, peak current, reference generator.

\section{INTRODUCTION}

$\mathbf{T}$ HE high penetration level of renewable energy sources and distributed generation (DG) plants has led to a change in the requirements for ancillary services, particularly during grid faults. Among these new services, low-voltage ride-through in wind plants, photovoltaic parks and other grid connected power devices is gaining an increasing attention due to their capability to improve grid efficiency, safety and reliability.

Low-voltage ride-through was first required to withstand voltage sags. Therefore, power plants could remain connected and avoid sudden tripping and loss of power generation. As DG penetration was increased [1], network operators introduced reactive power injection to support the grid voltage and to reduce the possibility of voltage collapse. Next generation of grid codes could demmand negative sequence current injection when needed [2], and rated current to better exploit reactive

Manuscript received January 17, 2014; revised April 19, 2014 and July 18, 2014; accepted July 25, 2014.

Copyright (C) 2014 IEEE. Personal use of this material is permitted. However, permission to use this material for any other purposes must be obtained from the IEEE by sending a request to pubs-permissions@ieee.org.

This work was supported by the Spanish Ministry of Economy and Competitiveness under Grant ENE2012-37667-C02-02 and CYTED programme under Grant 713RT0475.

A. Camacho, M. Castilla, J. Miret and L. G. de Vicuña are with the Department of Electronic Engineering, Technical University of Catalonia, 08800 Vilanova i la Geltrú, Spain (e-mail: antonio.camacho.santiago@upc.edu; miquel.castilla@upc.edu; jmiret@eel.upc.edu; vicuna@eel.upc.edu)

A. Borrell is with the Department of Electrical Engineering, Escola Universitària Salesiana de Sarrià, Autonomous University of Barcelona, 08017 Barcelona, Spain (e-mail: aborrell@euss.es) power provisions [3]. Under these requirements, improved services could be attended, and new control schemes may be developed. The new distributed nature of these power systems allows for a wide range of control strategies since DG is required to operate flexibly and to enhance the services provided to the grid.

To avoid the disconnection of power suppliers, the injected phase currents should be safely controlled at any instant. The problem of controlling the amplitude of the phase currents becomes more complex during unbalanced grid faults, mainly because the trend of simultaneously inject active and reactive power via positive and negative sequences. In such cases, the injection of positive and negative sequence power inherently induce different amplitudes in the injected phase currents. However, some interesting benefits can be obtained with these flexible strategies as will be shown later. It should be mentioned that a different approach to control the amplitude of the injected currents could be to find the current references instead of the power references. However, the power approach is mostly used in power converters control.

Thus, a fully flexible reference generator with peak current limitation, which is the main contribution of this paper, can be useful to develop novel strategies and to avoid overcurrent tripping. This new requirements are emerging from grid operators due to the fact that DG participation in the total power production is constantly increasing. Therefore, inverterbased DG are one of the key components to flexibilize the operation during voltage sags, and to define the behaviour of grid connected power systems under such contingencies.

From the source's point of view, the main problem during grid faults is the loss of power capacity to inject the active power production. As a result, dc-link voltage begin to increase and can lead to inverter tripping. To avoid this problem, some safety mechanisms must be activated, as for example crowbars to elliminate the excess of active power production, or to develop ride-through strategies to minimize the problem.

Advanced control algorithms for low-voltage ride-through are mainly based on symmetric sequences [4]-[19]. Some of these studies have been proposed to achieve particular control objectives related to the current loop, power oscillations, power quality, dc-link ripple or voltage support during grid faults. However, few works have been developed for peak current limitation during unbalanced voltage sags [13]-[19], and they are not fully flexible since only particular cases are investigated to simplify the study. In [13], only active power is injected and no limitation is considered. In [14]-[17], only 


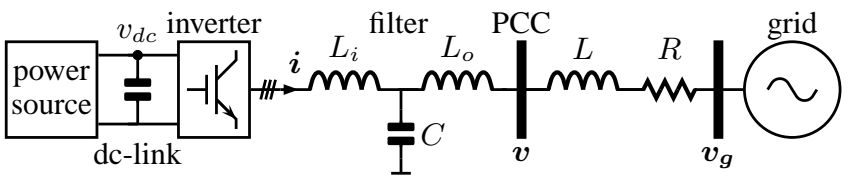

Fig. 1. Simplified scheme of a three-phase grid-connected DG inverter.

reactive power is taken under consideration. In [18], only some of the control proposals ensure peak current limitation. Lastly, [19] develops a very interesting work although negative sequence active power is not considered.

Previous works in peak current limitation lack of fully flexible operation during unbalanced voltage sags, which is the main objective of the proposed work. The control approach presented in this paper computes the power references for different low-voltage ride-through strategies while maintaining the injected current safely controlled to a predefined maximum value. The proposed reference generator with peak current limitation can be fully tuned to achieve different low-voltage ride-through strategies by selecting an active and a reactive control gain. The selection of these control gains will be discussed, and depends on two main aspects, a look-up table defined by the grid operators for high rated power plants depending on the sag depth, or an on-line selection to achieve particular ride-through strategies, as for example the new phase power equalization strategy when low power systems are considered. These two methods for selecting the gains are developed along the work, and to demonstrate the flexibility of the reference generator, the phase power equalization and the active power curtailment strategies are validated by means of experimental tests.

Thus, the paper contribution is two-fold: first, to integrate a peak current limiter fully flexible, and second, to develop novel low-voltage ride-through strategies to improve the performance against grid faults. The first contribution ensures that the power inverter can inject power into the grid without exceeding the maximum allowable phase current. Therefore, it can avoid the overcurrent tripping and the disconnection. The second contribution presents some flexible operation modes to ride-through voltage sags. These two contributions present some advantages respect to previously works proposed in the literature: the reference generator is fully flexible, the proposal can prioritize between active or reactive power according to external requirements, and a easy mechanism of tunning two control gains allows for different services during sags.

The paper is organized as follows. Section II introduces the DG plant and the control scheme during grid faults. Section III develops the reference generator with peak current limiter. Section IV presents the different ride-through services and shows the resulting benefits by means of experimental tests. Finally, section V concludes the work.

\section{Plant And Control}

DG inverters are considered a key element to improve grid operation. Among the inverters architectures, full-scale power converters are becoming the preferred choice in wind turbine technology because of their flexibility [20]. To attain

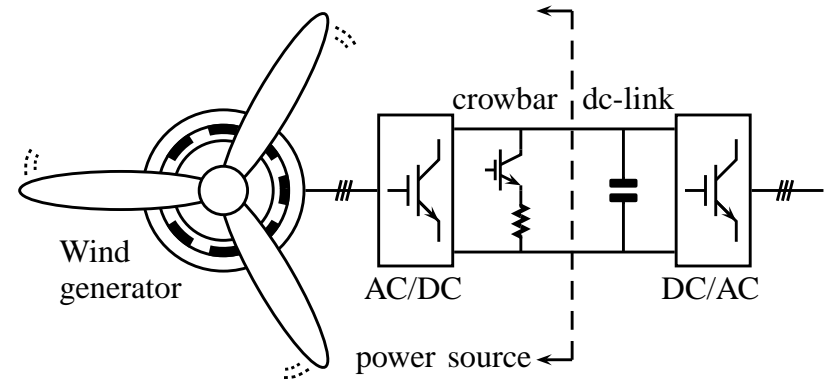

Fig. 2. Simplified scheme of a wind power source with full-scale converter.

this flexibility, the control schemes must be adapted to fulfill stringent fault requirements. In this section, two basic aspects of grid connected DG inverters are described: firstly, the basic plant configuration with the main elements involved during grid faults, and secondly the control parts required to develop the proposal for any voltage sag.

\section{A. Plant Description}

Fig. 1 shows the typical configuration of a three-phase three-wire grid connected inverter. The complete system is composed of the power source, the inverter and the grid. The interconnection between the power source and the inverter is operated by a dc-link capacitor. The inverter consists of a three leg voltage source PWM inverter with LCL filter, or LC filter plus step-up transformer. Finally, the inverter is connected to the grid at the point of common coupling (PCC). The grid is modeled as an equivalent $R L$ impedance in series with an unbalanced voltage source.

A key aspect in DG power control during grid faults is the type of power source. Fig.2 shows the future trend for megawatt size wind turbines. A full-scale power converter between the generator and the grid allows for higher flexibility although switching losses are increased [21]. The wind power source scheme presented in Fig. 2 shows an AC to DC stage followed by a $\mathrm{DC}$ to $\mathrm{AC}$ inverter which is the focus of this study. In between, the dc-link is in charge of balancing power transfer as previously stated for Fig. 1. Also, a crowbar is required in this type of power converters to avoid dc-link overvoltage during grid faults. The crowbar activates when more active power is produced than injected into the grid. To simplify the study, the proposed control scheme is focused on the inverter side control as presented in Fig. 1.

\section{B. Control Under Grid Faults}

The behavior of the three-phase inverter under grid faults is determined by the injected current at the PCC. Thus, a proper current-mode control to ride through voltage sags is required. Fig. 3 shows the control block diagram during grid faults.

The inputs of the controller are the measured phase voltages at the PCC $\boldsymbol{v}$, the currents $i$ flowing through $L_{i}$ inductor, and the dc-link voltage $v_{d c}$. Voltage $\boldsymbol{v}$ and currents $\boldsymbol{i}$ are transformed into the $\alpha \beta$ domain by using Clarke transformation. Voltages $v_{\alpha}$ and $v_{\beta}$ are then decomposed into symmetric components using a sequence extractor. Many sequence extractors can be found in the literature to extract voltage sag information 


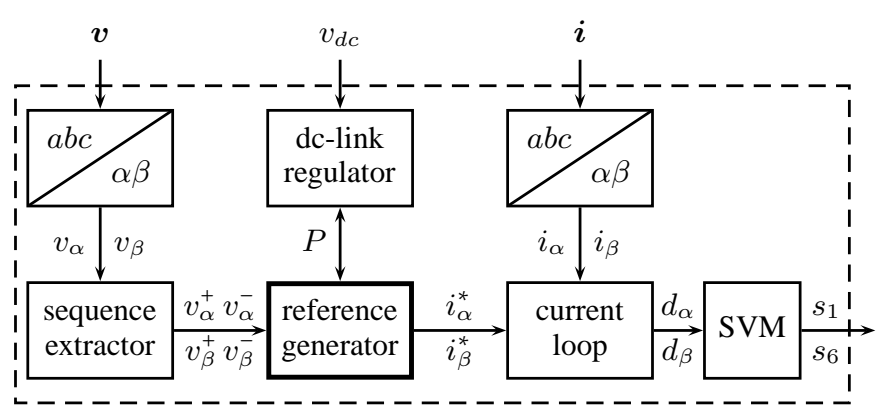

Fig. 3. Control diagram of three-phase inverter under grid fault.

$v_{\alpha}^{+}, v_{\beta}^{+}, v_{\alpha}^{-}$and $v_{\beta}^{-}$at run-time [22]-[29]. In addition, a dc-link voltage regulator is in charge of the active power reference $P$ to keep power balance. Next, the reference generator block is the kernel of this proposal since it processes the grid voltage for any given grid fault and obtains the set points that limits the peak current to a predefined value. Hence, the phase currents can be safely controlled. The next stage corresponds to the current loop, where the references are compared with the measured currents. At the end of the current control loop, duty cycles $d_{\alpha}$ and $d_{\beta}$ are processed by the space vector pulse width modulator (SVM) to drive the switches $s_{1}, s_{2}, \ldots s_{6}$.

\section{Conventional vs. Proposed Control}

This section develops the step by step procedure to keep safely controlled the injected currents during grid faults. First, the conventional power references for the balanced grid case are developed, and then the proposed reference generator for unbalanced faults is derived.

\section{A. Conventional Control for Balanced Grid Voltages}

Assume that the active power production in some time interval is $P$. Due to external requirements, the inverter is forced to support the grid with reactive power $Q$, and should deliver the rated current of the inverter $I_{\max }$. The objective is to improve the utilization of reactive power provisions by setting the reactive reference to some value such as

$$
\max \left\{I_{a}, I_{b}, I_{c}\right\}=I_{\max }
$$

where $I_{a}, I_{b}$ and $I_{c}$ are the amplitudes of the phase currents.

Using Clarke transformation for three-wire systems, the stationary reference frame voltages are

$$
\left[\begin{array}{l}
v_{\alpha} \\
v_{\beta}
\end{array}\right]=\frac{1}{3}\left[\begin{array}{ccc}
2 & -1 & -1 \\
0 & \sqrt{3} & -\sqrt{3}
\end{array}\right]\left[\begin{array}{l}
v_{a} \\
v_{b} \\
v_{c}
\end{array}\right] .
$$

It should be noted that $v_{\alpha}=V \cos (\omega t)$ and $v_{\beta}=V \sin (\omega t)$, being $\omega$ the grid frequency.

From the basic power theory, the instantaneous active and reactive powers are

$$
\begin{aligned}
& p=\frac{3}{2}\left(v_{\alpha} i_{\alpha}+v_{\beta} i_{\beta}\right) \\
& q=\frac{3}{2}\left(-v_{\alpha} i_{\beta}+v_{\beta} i_{\alpha}\right) .
\end{aligned}
$$

Developing (3) and (4), the reference current generator can be formulated by using the reference powers $P$ and $Q$ as [30]

$$
\begin{aligned}
& i_{\alpha}^{*}=\frac{2}{3}\left[\frac{v_{\alpha}}{v_{\alpha}^{2}+v_{\beta}^{2}} P+\frac{v_{\beta}}{v_{\alpha}^{2}+v_{\beta}^{2}} Q\right] \\
& i_{\beta}^{*}=\frac{2}{3}\left[\frac{v_{\beta}}{v_{\alpha}^{2}+v_{\beta}^{2}} P+\frac{-v_{\alpha}}{v_{\alpha}^{2}+v_{\beta}^{2}} Q\right] .
\end{aligned}
$$

Assuming that the current loop is fast enough and properly tuned (i.e. $i_{\alpha}=i_{\alpha}^{*}$ and $i_{\beta}=i_{\beta}^{*}$ ), and using inverse Clarke transformation, the amplitudes of the phase currents are obtained

$$
I_{a}=I_{b}=I_{c}=\frac{2}{3} \frac{\sqrt{P^{2}+Q^{2}}}{V} .
$$

Finally, substituting $I_{a}=I_{\max }$ in the previous expression allows to limit the injected current to a predefined value. Solving (7) for $Q$, the reactive power reference which ensures a safe control of the injected currents is obtained

$$
Q=\frac{1}{2} \sqrt{\left(3 I_{\max } V\right)^{2}-(2 P)^{2}} .
$$

From (8), two aspects should be noticed: first, the maximum active power production should comply $3 I_{\max } V \geq 2 P$ which clearly indicates the loss of power capacity when the voltage drops; and second, by injecting the computed reactive power $Q$, the currents are safely controlled to the predefined value.

\section{B. Proposed Control for Unbalanced Grid Voltages}

Previous subsection was devised for balanced grid conditions. However, the same reasoning can be applied to unbalanced grid conditions as proposed below. The same control objectives as the balanced case can be formulated for the unbalanced scenario: feed the grid with the active power production, support the grid with reactive power and inject the rated current of the inverter. Also, due to the voltage imbalance, the fully flexible control proposal can achieve these objectives by injecting different ammounts of active and reactive power via positive and negative sequence in order to obtain different ride-through services.

During unbalanced grid voltages, the positive and negative sequence voltages $v_{\alpha}^{+}, v_{\beta}^{+}, v_{\alpha}^{-}$and $v_{\beta}^{-}$can be expressed as

$$
\begin{aligned}
v_{\alpha}^{+} & =V^{+} \cos \left(\omega t+\varphi^{+}\right) \\
v_{\alpha}^{-} & =V^{-} \cos \left(\omega t-\varphi^{-}\right) \\
v_{\beta}^{+} & =V^{+} \cos \left(\omega t-\frac{\pi}{2}+\varphi^{+}\right) \\
v_{\beta}^{-} & =V^{-} \cos \left(\omega t+\frac{\pi}{2}-\varphi^{-}\right)
\end{aligned}
$$

where $V^{+}$and $V^{-}$are the amplitudes of the positive and negative sequence voltages respectively, and $\varphi^{+}$and $\varphi^{-}$are the phase angle jumps. The phase angle between sequences is defined as

$$
\varphi=\varphi^{+}-\varphi^{-}
$$

It should be noted that $v_{\alpha}=v_{\alpha}^{+}+v_{\alpha}^{-}$and $v_{\beta}=v_{\beta}^{+}+v_{\beta}^{-}$. To further characterize the unbalanced voltage, the following is 
required

$$
\begin{aligned}
V^{+} & =\sqrt{\left(v_{\alpha}^{+}\right)^{2}+\left(v_{\beta}^{+}\right)^{2}} \\
V^{-} & =\sqrt{\left(v_{\alpha}^{-}\right)^{2}+\left(v_{\beta}^{-}\right)^{2}} \\
\cos (\varphi) & =\frac{v_{\alpha}^{+} v_{\alpha}^{-}-v_{\beta}^{+} v_{\beta}^{-}}{V^{+} V^{-}} \\
\sin (\varphi) & =\frac{v_{\alpha}^{+} v_{\beta}^{-}+v_{\beta}^{+} v_{\alpha}^{-}}{V^{+} V^{-}} .
\end{aligned}
$$

And to compact the notation, the voltage unbalance factor $u$ is defined as [31]

$$
u=\frac{V^{-}}{V^{+}} .
$$

Similarly to (3) and (4), the power components during unbalanced grid conditions are

$$
\begin{aligned}
& p=p^{+}+p^{-}+\widetilde{p} \\
& q=q^{+}+q^{-}+\widetilde{q}
\end{aligned}
$$

where $p^{+}$and $p^{-}$are the positive and negative instantaneous active power respectively, $q^{+}$and $q^{-}$the reactive ones, and $\widetilde{p}$ and $\widetilde{q}$ are oscillating terms at twice the grid frequency with zero mean value. The formulation for the power components is as follows

$$
\begin{aligned}
p^{+} & =\frac{3}{2}\left(v_{\alpha}^{+} i_{\alpha}^{+}+v_{\beta}^{+} i_{\beta}^{+}\right) \\
p^{-} & =\frac{3}{2}\left(v_{\alpha}^{-} i_{\alpha}^{-}+v_{\beta}^{-} i_{\beta}^{-}\right) \\
\widetilde{p} & =\frac{3}{2}\left(v_{\alpha}^{+} i_{\alpha}^{-}+v_{\beta}^{+} i_{\beta}^{-}+v_{\alpha}^{-} i_{\alpha}^{+}+v_{\beta}^{-} i_{\beta}^{+}\right) \\
q^{+} & =\frac{3}{2}\left(-v_{\alpha}^{+} i_{\beta}^{+}+v_{\beta}^{+} i_{\alpha}^{+}\right) \\
q^{-} & =\frac{3}{2}\left(-v_{\alpha}^{-} i_{\beta}^{-}+v_{\beta}^{-} i_{\alpha}^{-}\right) \\
\widetilde{q} & =\frac{3}{2}\left(-v_{\alpha}^{+} i_{\beta}^{-}+v_{\beta}^{+} i_{\alpha}^{-}-v_{\alpha}^{-} i_{\beta}^{+}+v_{\beta}^{-} i_{\alpha}^{+}\right) .
\end{aligned}
$$

The current reference generator under these unbalanced conditions becomes

$$
\begin{aligned}
& i_{\alpha(p)}^{*}=\frac{2}{3}\left[\frac{v_{\alpha}^{+}}{\left(v_{\alpha}^{+}\right)^{2}+\left(v_{\beta}^{+}\right)^{2}} P^{+}+\frac{v_{\alpha}^{-}}{\left(v_{\alpha}^{-}\right)^{2}+\left(v_{\beta}^{-}\right)^{2}} P^{-}\right] \\
& i_{\beta(p)}^{*}=\frac{2}{3}\left[\frac{v_{\beta}^{+}}{\left(v_{\alpha}^{+}\right)^{2}+\left(v_{\beta}^{+}\right)^{2}} P^{+}+\frac{v_{\beta}^{-}}{\left(v_{\alpha}^{-}\right)^{2}+\left(v_{\beta}^{-}\right)^{2}} P^{-}\right] \\
& i_{\alpha(q)}^{*}=\frac{2}{3}\left[\frac{v_{\beta}^{+}}{\left(v_{\alpha}^{+}\right)^{2}+\left(v_{\beta}^{+}\right)^{2}} Q^{+}+\frac{v_{\beta}^{-}}{\left(v_{\alpha}^{-}\right)^{2}+\left(v_{\beta}^{-}\right)^{2}} Q^{-}\right] \\
& i_{\beta(q)}^{*}=\frac{-2}{3}\left[\frac{v_{\alpha}^{+}}{\left(v_{\alpha}^{+}\right)^{2}+\left(v_{\beta}^{+}\right)^{2}} Q^{+}+\frac{v_{\alpha}^{-}}{\left(v_{\alpha}^{-}\right)^{2}+\left(v_{\beta}^{-}\right)^{2}} Q^{-}\right] .
\end{aligned}
$$

The total reference current in each channel is

$$
\begin{aligned}
& i_{\alpha}^{*}=i_{\alpha(p)}^{*}+i_{\alpha(q)}^{*} \\
& i_{\beta}^{*}=i_{\beta(p)}^{*}+i_{\beta(q)}^{*} .
\end{aligned}
$$

To further detail the current components, note that each expression in (27)-(30) has a positive and a negative sequence term

$$
\begin{array}{lll}
i_{\alpha(p)}^{*}=i_{\alpha\left(p^{+}\right)}^{*}+i_{\alpha\left(p^{-}\right)}^{*} & , & i_{\alpha(q)}^{*}=i_{\alpha\left(q^{+}\right)}^{*}+i_{\alpha\left(q^{-}\right)}^{*} \\
i_{\beta(p)}^{*}=i_{\beta\left(p^{+}\right)}^{*}+i_{\beta\left(p^{-}\right)}^{*} & , & i_{\beta(q)}^{*}=i_{\beta\left(q^{+}\right)}^{*}+i_{\beta\left(q^{-}\right)}^{*} .
\end{array}
$$

Furthermore, the positive and negative sequence currents in (21)-(26) are

$$
\begin{array}{lll}
i_{\alpha}^{+}=i_{\alpha\left(p^{+}\right)}^{*}+i_{\alpha\left(q^{+}\right)}^{*} & , & i_{\beta}^{+}=i_{\beta\left(p^{+}\right)}^{*}+i_{\beta\left(q^{+}\right)}^{*} \\
i_{\alpha}^{-}=i_{\alpha\left(p^{-}\right)}^{*}+i_{\alpha\left(q^{-}\right)}^{*} & , & i_{\beta}^{-}=i_{\beta\left(p^{-}\right)}^{*}+i_{\beta\left(q^{-}\right)}^{*} .
\end{array}
$$

Note that the current reference generator in (27)-(30) has 4 degrees of freedom: $P^{+}, P^{-}, Q^{+}$and $Q^{-}$. Hence, there exist multiple combinations of these power references which can ensure peak current limitation. The objective of the proposed control scheme is to impose some relations among $P^{+}, P^{-}, Q^{+}$ and $Q^{-}$to achieve different ride-through services. A method for so is to define an active $k_{p}$ and a reactive $k_{q}$ control gains as

$$
k_{p}=\frac{P^{+}}{P} \quad, \quad k_{q}=\frac{Q^{+}}{Q} .
$$

Since $P^{+}+P^{-}=P$ and $Q^{+}+Q^{-}=Q$, it can be observed from (37) that

$$
\begin{array}{lll}
P^{+}=k_{p} P & , \quad P^{-}=\left(1-k_{p}\right) P \\
Q^{+}=k_{q} Q & , & Q^{-}=\left(1-k_{q}\right) Q .
\end{array}
$$

From (37)-(39), 4 degrees of freedom still exist $k_{p}, k_{q}, P$ and $Q$. However the physical meaning of these values is different from $P^{+}, P^{-}, Q^{+}$and $Q^{-}$. This method to derive the reference currents allows for simpler ride-through services as will be shown in next section. Therefore, by selecting $k_{p} \rightarrow 1$ for example, $P^{+} \rightarrow P$, and the active power tends to be injected via positive sequence. However, by selecting $k_{p} \rightarrow 0, P^{-} \rightarrow P$, and the tendency is to only inject negative sequence active power. The same reasoning holds for $k_{q}$ and the reactive components.

Similarly to the voltage sequence amplitudes, the amplitudes of the positive and negative sequence currents can be derived. By inserting (9)-(12) and (37) into (27)-(30)

$$
\begin{aligned}
& I_{p}^{+}=\frac{2}{3} \frac{P^{+}}{V^{+}}=\frac{2}{3} \frac{k_{p} P}{V^{+}} \\
& I_{p}^{-}=\frac{2}{3} \frac{P^{-}}{V^{-}}=\frac{2}{3} \frac{\left(1-k_{p}\right) P}{V^{-}} \\
& I_{q}^{+}=\frac{2}{3} \frac{Q^{+}}{V^{+}}=\frac{2}{3} \frac{k_{q} Q}{V^{+}} \\
& I_{q}^{-}=\frac{2}{3} \frac{Q^{-}}{V^{-}}=\frac{2}{3} \frac{\left(1-k_{q}\right) Q}{V^{-}}
\end{aligned}
$$

where $I_{p}^{+}$is the positive sequence active current amplitude, $I_{p}^{-}$the negative one, and $I_{q}^{+}$and $I_{q}^{-}$the reactive counterparts. Due to the fact that positive active and reactive currents are $90^{\circ}$ delayed, and the same applies to negative sequence components, then

$$
\begin{aligned}
& I^{+}=\sqrt{\left(I_{p}^{+}\right)^{2}+\left(I_{q}^{+}\right)^{2}} \\
& I^{-}=\sqrt{\left(I_{p}^{-}\right)^{2}+\left(I_{q}^{-}\right)^{2}} .
\end{aligned}
$$

Developing (27)-(30) and (40)-(45), and applying inverse Clarke transformation, the amplitudes of the phase currents are obtained

$$
\begin{aligned}
& I_{a}=\sqrt{\left(I^{+}\right)^{2}+\left(I^{-}\right)^{2}+2 I^{+} I^{-} \cos (\theta)} \\
& I_{b}=\sqrt{\left(I^{+}\right)^{2}+\left(I^{-}\right)^{2}+2 I^{+} I^{-} \cos (\theta-2 / 3 \pi)} \\
& I_{c}=\sqrt{\left(I^{+}\right)^{2}+\left(I^{-}\right)^{2}+2 I^{+} I^{-} \cos (\theta+2 / 3 \pi)}
\end{aligned}
$$


where

$$
\theta=\operatorname{tg}^{-1}\left(\frac{Q^{+}}{P^{+}}\right)+\operatorname{tg}^{-1}\left(\frac{Q^{-}}{P^{-}}\right)-\varphi
$$

When (40)-(45) are inserted in (46)-(49), only one variable $Q$ remains unknown since $P$ is derived from the active power production of the power source, and $k_{p}$ and $k_{q}$ are externally selected to achieve different ride-through services as will be shown in next section.

An in depth analysis of (46)-(48) shows that there exists a separate solution for $Q$ in each expression that ensures peak current limitation, i.e. there exists a solution labeled $Q_{a}$ which complies that $I_{a}=I_{\max }$, another solution for $Q_{b}$ to set $I_{b}=I_{\max }$ and finally the last solution $Q_{c}$ for $I_{c}=I_{\max }$. Among these three solutions the minimum of the three reactive power solutions ensures that the maximum phase current will be safely controlled to the rated value

$$
Q=\min \left\{Q_{a}, Q_{b}, Q_{c}\right\} \Rightarrow \max \left\{I_{a}, I_{b}, I_{c}\right\}=I_{\max } .
$$

These three solutions can be unified into one single expression. The solution for the reactive power reference which ensures peak current limitation is as follows

$$
Q=\frac{-2 x P+\sqrt{y\left(3 I_{\max } u V^{+}\right)^{2}-(2 z P)^{2}}}{2 y}
$$

where

$$
\begin{aligned}
& x=\left(k_{p}+k_{q}-2 k_{p} k_{q}\right) u \sin (\widehat{\varphi}) \\
& y=k_{q}^{2}\left[1+2 u \cos (\widehat{\varphi})+u^{2}\right]-2 k_{q}[1+u \cos (\widehat{\varphi})]+1 \\
& z=k_{p}[1-u \cos (\widehat{\varphi})]+k_{q}[1+u \cos (\widehat{\varphi})]+k_{p} k_{q}\left[u^{2}-1\right]-1
\end{aligned}
$$

and $\bar{\varphi}$ can only take three different values

$$
\widehat{\varphi}=\left\{\varphi, \varphi+\frac{2}{3} \pi, \varphi-\frac{2}{3} \pi\right\}
$$

to obtain the three different solutions $Q_{a}, Q_{b}$ and $Q_{c}$ respectively.

It is worth mentioning that a current approach instead of a power approach can be developed to ensure peak current limitation. In such a case, the positive and negative references for the active and reactive powers $P^{+}, P^{-}, Q^{+}$and $Q^{-}$will be replaced by the amplitude of the active and reactive currents $I_{p}^{+}, I_{p}^{-}, I_{q}^{+}$and $I_{q}^{-}$. To develop this procedure, the reference generator in (27)-(30) need to be modified accordingly. The power references are preferred in power conversion control although both approaches will produce the same results.

\section{Numerical Example}

Assume that an unbalanced voltage sag occurs with the following PCC measures: $V^{+}=140 \mathrm{~V}, V^{-}=40 \mathrm{~V}$ and $\varphi=-50^{\circ}$. The active power production is $P=700 \mathrm{~W}$, and the network operator demands to inject reactive power and rated current of the inverter $I_{\max }=10 \mathrm{~A}$. Also, due to the unbalanced nature of the grid voltage, some positive and negative sequence powers are required, for example $k_{p}=\frac{P^{+}}{P}=0.9$ and $k_{q}=\frac{Q^{+}}{Q}=0.5$. As previously stated, only $Q$ remains unknown, see (38)-(39).

Substituting previous data in (51)-(54), three reactive power references should be computed. The solution for phase $a$ is obtained when $\bar{\varphi}=\varphi$, and the resulting value is $Q_{a}=1829 \mathrm{VAr}$. For the phase $b, \hat{\varphi}=\varphi+\frac{2}{3} \pi$, resulting in $Q_{b}=806$ VAr. Lastly for phase $c, \hat{\varphi}=\varphi-\frac{2}{3} \pi$, and the reactive power reference is $Q_{c}=1014 \mathrm{VAr}$. Finally, to ensure the safe current control, the minimum of the three previous results is selected, see (50), and the reactive power reference is $\min \left\{Q_{a}, Q_{b}, Q_{c}\right\}=806 \mathrm{VAr}$.

Once the total reactive power reference has been computed, the components for positive and negative active and reactive power are all known: $P^{+}=k_{p} P=630 \mathrm{~W}, P^{-}=\left(1-k_{p}\right) P=$ $70 \mathrm{~W}, Q^{+}=k_{q} Q=403 \operatorname{VAr}, Q^{-}=\left(1-k_{q}\right) Q=403 \mathrm{VAr}$. These references are passed to the reference generator in (27)-(30). As expected, the peak currents when selecting this strategy are $I_{a}=4.0 \mathrm{~A}, I_{b}=10.0 \mathrm{~A}$ and $I_{c}=7.8 \mathrm{~A}$. Hence, the objectives of the reference generator are simultaneously accomplished:

- injection of the maximum inverter current $I_{\max }$

- injection of the active power production $P$

- injection of reactive power $Q$ to support the grid voltage

- balance the amount of positive and negative active and reactive powers

\section{Control Strategies}

In this section, two control strategies are developed. The strategies share a common objective: limit the maximum peak current to a safe predefined value $I_{\max }$, which has been selected as $10 \mathrm{~A}$ throughout the paper due to the experimental limitations. Also, the selection of the control gains is discussed during the strategies, since the proposed reference generator is capable to provide some services by selecting appropiately the value of $k_{p}$ and $k_{q}$. The first test presents a phase power equalization strategy in combination with the peak current limiter. The final purpose of this strategy is to show the capability of the reference generator to fix the desired behaviour even in time varying voltage sags, as for example to dynamically change the values of the gains to achieve a given objective, the equalization of the amount of power injected in each phase.

The second strategy deals with higher active power production and high priority for reactive power requirements, as for example the requirements from grid operators to support the grid voltage in inductive grids with high contribution of the DG to the total power of the grid. In this second strategy, the proposed reference generator in (51)-(54) is formulated for the active power reference $P$ instead of $Q$. Then, the active power reference is on-line computed to feed the grid according to the remaining current capacity of the inverter. The active power curtailment strategy is required in present grid codes where supporting the grid during grid faults is mandatory. Under these perturbations, the reactive power has higher priority, and the active power is balanced depending on the sag depth. However, actual grid codes are only focused on positive sequence active and reactive powers. Thus, the proposed strategy goes one step beyond to further explode the capabilities of these systems during unbalanced sags. At the end of the experimental strategies, a detailed evaluation of each one is discussed.

The results for each control strategy are experimentally tested under the same grid fault, which is presented as a base test for comparison. 
TABLE I

SYSTEM PARAMETERS

\begin{tabular}{lcc}
\hline \hline & Symbol & Nominal value \\
\hline dc-link voltage & $v_{d c}$ & $350 \mathrm{~V}$ \\
inverter inductance & $L_{i}$ & $5 \mathrm{mH}$ \\
filter capacitor & $C$ & $1.4 \mu \mathrm{F}$ \\
output inductance & $L_{o}$ & $2 \mathrm{mH}$ \\
grid inductance & $L$ & $0.8 \mathrm{mH}$ \\
grid resistance & $R$ & $0.02 \Omega$ \\
grid voltage & $v_{g}$ & $155 \mathrm{~V}(1-\mathrm{n}$, peak $), 60 \mathrm{~Hz}$ \\
switching frequency & $f_{s}$ & $10 \mathrm{kHz}$ \\
rated current & $I_{\max }$ & $10 \mathrm{~A}(\mathrm{peak})$ \\
\hline & &
\end{tabular}

\section{A. Base Test}

Based on the scheme in Fig. 1, a test platform has been built using an Amrel SPS-800-12 DC Power Source, a Semikron three-phase IGBT bridge with LCL filter and a Pacific Power AMX AC Power Source to emulate the grid and get repetitive faults. In Table I, the nominal values of the system parameters are collected. The control algorithm is implemented on a Texas Instruments TMS320F28335 floating point Digital Signal Processor.

The controller includes four main parts

1) sag detector

2) sequence extractor

3) proposed reference generator

4) proportional+resonant current controller

The sag detector detects the grid fault by computing the phase voltages root mean square values. Once the fault has been detected, the ride-through process is started. The sequence extractor processes the voltage measurements to extract voltage sequences at run-time. The digital implementation of the extractor is based on [23] and last one grid cycle approximately to update their values. Next stage during the implementation corresponds to the proposed reference generator to limit the peak current injection (51)-(54). This stage constitutes the focus of the present study. Finally, the reference currents are compared with the measured currents in a proportional+resonant controller to compute the duty cycles of the inverter switches.

A voltage sag has been programmed into the $\mathrm{AC}$ power source. The characteristics of the voltage sag are presented in Fig. 4. The sag is time-varying and has two transient segments to emulate real behavior of complex grid faults. Instantaneous phase voltages are plotted in the top of the figure, the rms values in the middle, and the amplitudes of the positive and negative sequence voltage in the bottom part.

\section{B. Phase Power Equalization}

As previously stated, the flexible reference generator can perform serveral ride-through strategies to achieve particular services during grid faults. Some of these strategies have been previosuly presented in the literature, as for example the minimization of dc-link voltage oscillations [6]. In the following subsection the phase power equalization is firstly presented and developed.

The purpose of this strategy is to equalize the active and the reactive power of each phase, i.e. to inject the same mean

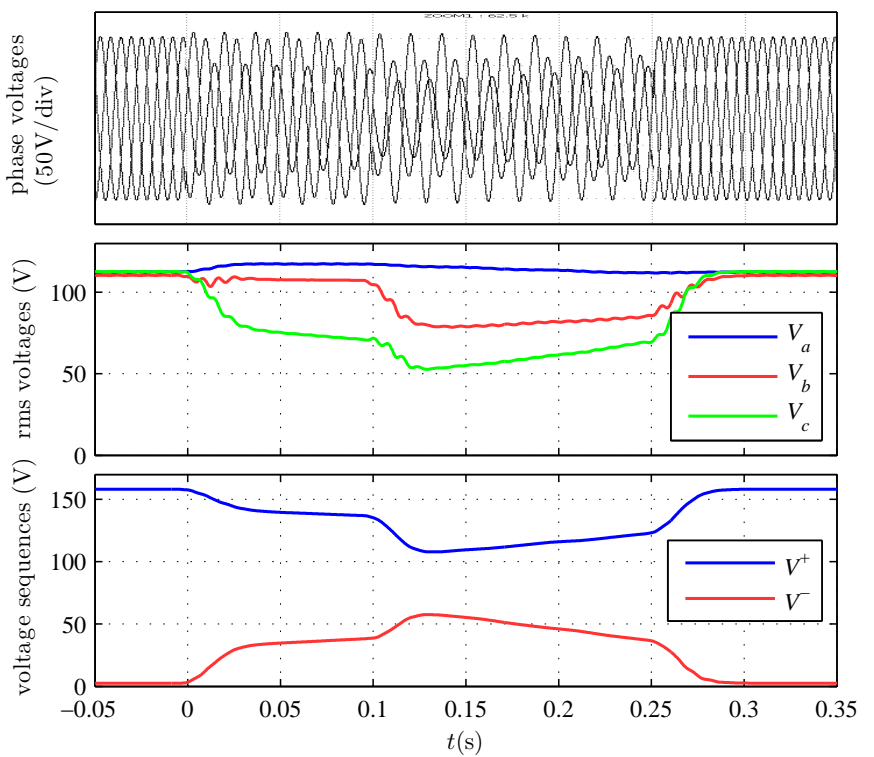

Fig. 4. Base test: Voltage sag characterization

active and reactive power in each phase

$$
P_{a}=P_{b}=P_{c}=\frac{P}{3} \quad, \quad Q_{a}=Q_{b}=Q_{c}=\frac{Q}{3} .
$$

This strategy is of interest for local loads that require special attention as for example constant power loads. These loads are characterized by consuming constant power regardless of the grid voltage. Therefore, these elements, which are mostly interfaced by switched converters could improve their grid fault immunity [32], [33]. Also, safe control of the injected currents must be ensured.

The test objectives can be summarized as:

- keep feeding the grid with the same active power production as before the sag $P=400 \mathrm{~W}$,

- inject rated current of the inverter $I_{\max }=10 \mathrm{~A}$ by supporting the grid voltage with reactive power $Q$,

- select the control gains $k_{p}$ and $k_{q}$ in such a way that active and reactive phase powers were equalized.

The active and reactive instantaneous power in each phase can be expressed as

$$
\begin{aligned}
& p_{a}=v_{a} i_{a}=P_{a}+\widetilde{p_{a}} \quad, \quad q_{a}=\frac{v_{b}-v_{c}}{\sqrt{3}} i_{a}=Q_{a}+\widetilde{q_{a}} \\
& p_{b}=v_{b} i_{b}=P_{b}+\widetilde{p_{b}} \quad, \quad q_{b}=\frac{v_{c}-v_{a}}{\sqrt{3}} i_{b}=Q_{b}+\widetilde{q_{b}} \\
& p_{c}=v_{c} i_{c}=P_{c}+\widetilde{p_{c}} \quad, \quad q_{c}=\frac{v_{a}-v_{b}}{\sqrt{3}} i_{c}=Q_{c}+\widetilde{q_{c}}
\end{aligned}
$$

where $p_{a}, p_{b}$ and $p_{c}$ are the instantaneous active phase powers, $q_{a}, q_{b}$ and $q_{c}$ are the reactive ones, $P_{a}, P_{b}, P_{c}, Q_{a}, Q_{b}$ and $Q_{c}$ are the average or dc-quantity of their corresponding phase powers, and $\widetilde{p_{a}}, \widetilde{p_{b}}, \widetilde{p_{c}}, \widetilde{q_{a}}, \widetilde{q_{b}}$ and $\widetilde{q_{c}}$ are oscillating terms with zero mean value. Developing these expressions for phase $a$, 

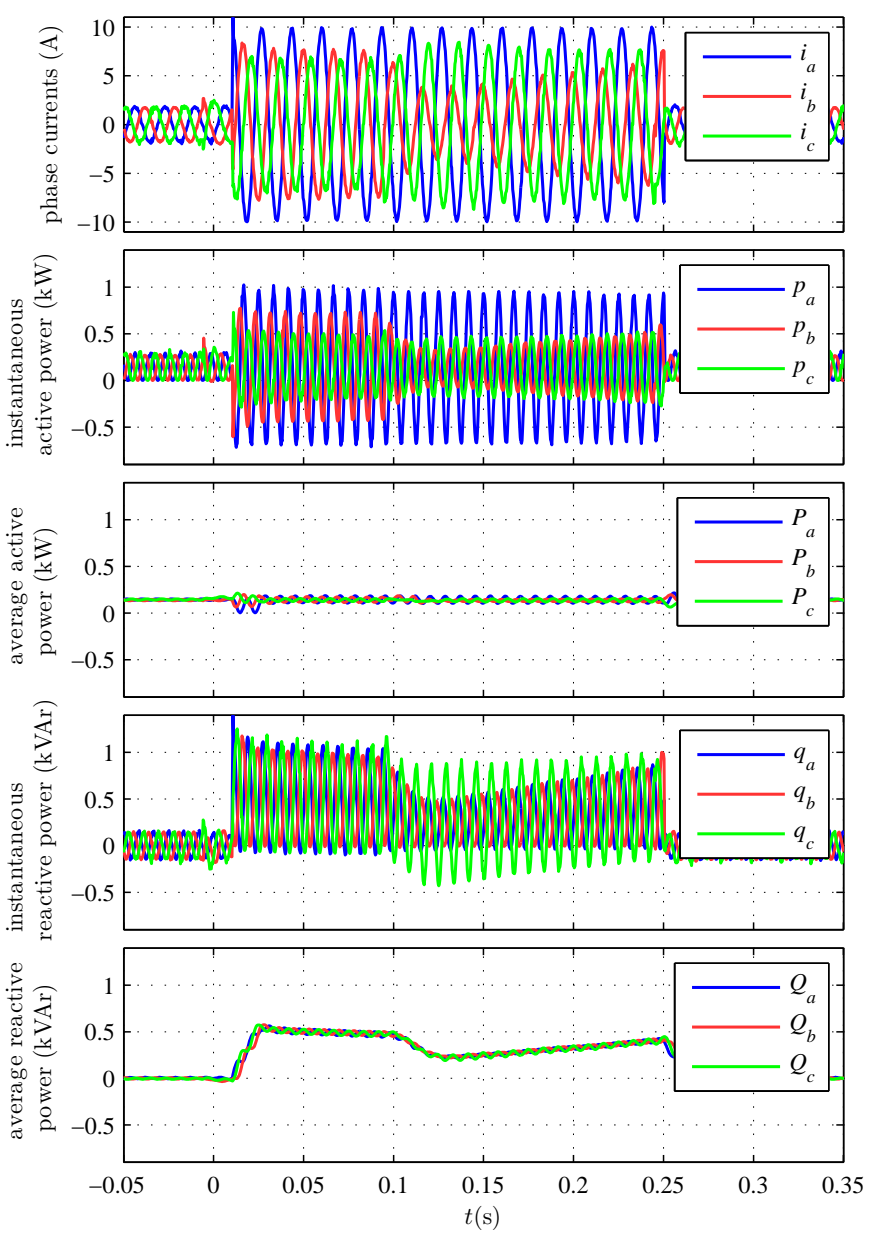

Fig. 5. Strategy I: Phase power equalization

the following is obtained

$$
\begin{aligned}
P_{a} & =\frac{P}{3}+\frac{P\left(k_{p} u^{2}-k_{p}+1\right)}{3 u} \sin (\varphi)+\frac{Q\left(k_{q} u^{2}-k_{q}+1\right)}{3 u} \cos (\varphi) \\
Q_{a} & =\frac{Q}{3}+\frac{P\left(k_{p} u^{2}-k_{p}+1\right)}{3 u} \sin (\varphi)-\frac{Q\left(k_{q} u^{2}-k_{q}+1\right)}{3 u} \cos (\varphi)
\end{aligned}
$$

From (56), (60) and (61), the control gain selection to equalize the phase powers should be selected as

$$
k_{p}=\frac{1}{1-u^{2}} \quad, \quad k_{q}=\frac{1}{1-u^{2}} .
$$

Fig. 5 shows the results for this equalizing strategy. Above in the figure, the injected currents show the proposed peak current control. Note that the currents are unbalanced, but the maximum amplitude is safely limited to $10 \mathrm{~A}$, as expected. In the second subplot, the instantaneous active phase powers are shown. These values have been computed according to (57)(59). Although each phase has different oscillation amplitudes $\widetilde{p_{a}} \neq \widetilde{p_{b}} \neq \widetilde{p_{c}}$, the mean value of each phase power is equal in the three phases, $P_{a}=P_{b}=P_{c}=\frac{P}{3}=\frac{400}{3} \mathrm{~W}$, as can be shown from the third plot where the average values over one grid cycle are computed. The same applies for the instantaneous reactive phase powers shown in the fourth subplot, and the average values $Q_{a}=Q_{b}=Q_{c}=\frac{Q}{3}$ which are shown below in the graph. The average reactive power evolve as the sag does in order to achieve the proposed objectives. Two important remarks are derived from this graph: the current is limited by the proposed reference generator regardless of the timevarying voltage sag, and the same average active and reactive power is injected in each phase, as expected from this strategy.

\section{Active Power Curtailment}

Power curtailment during grid faults is an important issue for DG power plants. The deeper the grid fault, the higher the reactive power requirements from network operators [3]. In extreme cases, $100 \%$ of reactive current is required. However, in sags produced far away from the connection point, both active and reactive power must be injected in order to simultaneously feed and support the grid. The problem becomes more complex when the active power production is high. In such a case, it is possible that the reactive power requirements plus the active power production exceeds the rated current limit. Therefore, the excess of production must be removed from the system in order to avoid dc-link overvoltage and tripping of the inverter. A method for this protection is the activation of DC-link crowbars (see Fig.2). Assuming that the network operator demands a certain amount of reactive power and a certain strategy for the active and reactive powers, it may be necessary to retail the injection of active power according to these needs.

The proposed reference generator can deal with these requirements by solving eq. (46)-(49) for the active power reference $P$ instead of $Q$

$$
P=\frac{-2 x Q+\sqrt{y\left(3 I_{\max } u V^{+}\right)^{2}-(2 z Q)^{2}}}{2 y}
$$

where

$$
\begin{aligned}
& x=\left(k_{p}+k_{q}-2 k_{p} k_{q}\right) u \sin (\widehat{\varphi}) \\
& y=k_{p}^{2}\left[1-2 u \cos (\widehat{\varphi})+u^{2}\right]-2 k_{p}[1-u \cos (\widehat{\varphi})]+1 \\
& z=k_{p}[1-u \cos (\widehat{\varphi})]+k_{q}[1+u \cos (\widehat{\varphi})]+k_{p} k_{q}\left[u^{2}-1\right]-1
\end{aligned}
$$

The same procedure as explained in Sec. III-B applies for this solution.

This strategy could have an important role in the behaviour of the inverter-based DG power systems during voltage sags. The grid operator can prioritize the voltage support, and balance the amount of positive and negative sequences to change the voltage profile at the PCC. Grid operators can define this behavior by defining a look-up table that sets the values for $k_{p}$ and $k_{q}$ in different scenerarios.

Next test shows how to inject the maximum active power $P$ when the reactive power reference $Q$, and the gains $k_{p}$ and $k_{q}$ have been externally selected. The active power production before the fault is $P=1000 \mathrm{~W}$, and the network operator states that

$$
\begin{aligned}
Q & =800 \mathrm{VAr} \\
k_{p} & =0.9 \\
k_{q} & =0.5 .
\end{aligned}
$$



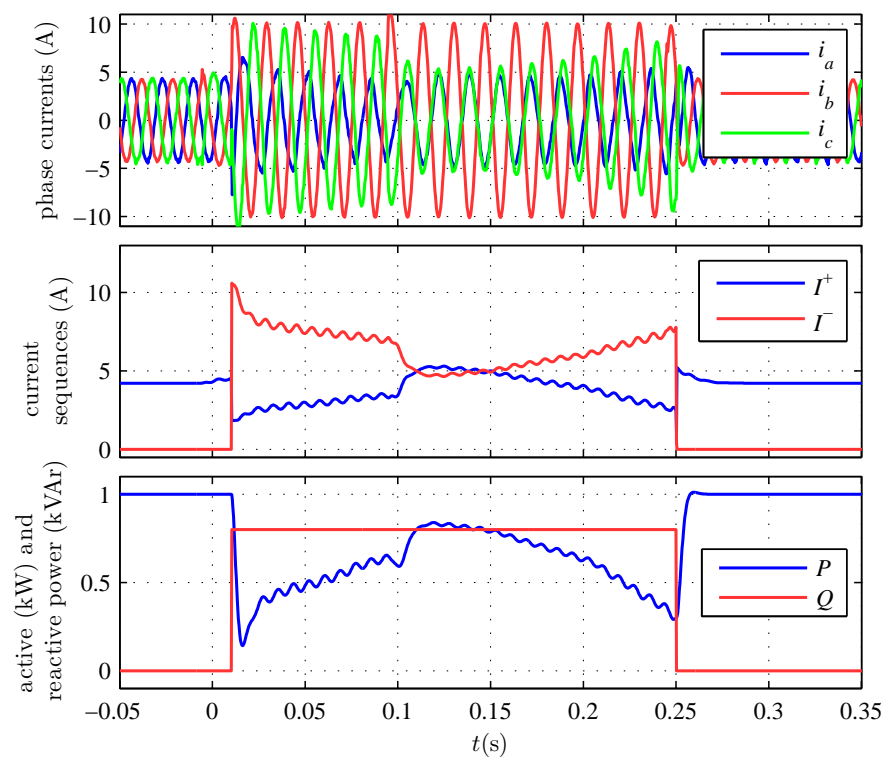

Fig. 6. Strategy II: Active power curtailment

Then, the new value for the active power can be computed based on (63)-(66) to keep the maximum current amplitude equal to $I_{\max }=10 \mathrm{~A}$.

Fig. 6 shows the results of the proposed strategy. Phase currents are displayed in the top of the figure. As expected, peak current limitation is ensured. In the middle, the amplitude of the positive and negative active and reactive currents, computed as (44)-(45), are shown. Finally, in the bottom of the figure, the active and reactive injected powers can be appreciated. Before the fault, $1000 \mathrm{~W}$ of active power feed the grid, however external requirements demand $Q=800 \mathrm{Var}$ and impose some restrictions among positive and negative powers. As a result, the active power injection drops to keep the injected currents safely controlled to the predefined value. As previously stated, the difference between active power production and grid injection need to be removed from the inverter to avoid DC-link overvoltage.

It is worth to mention that the selection of the control gains in previous strategies holds for this new active power reference computation. Therefore, the same benefits of other strategies can be adapted to an active power curtailment solution instead of a reactive power one.

\section{Discussion on the flexibility of the proposed control}

Based on the above set of experiments, further discussion is required. The main contribution of the paper is the reference generator presented in (51)-(54) which can be reformulated to prioritize the reactive power injection as shown in (63)(66). The control proposal could be applied to different size of power converters, from high to low rated power. In these extreme cases, different smart settings could be developed for each type of power source, although the proposed reference generator can deal with these two extreme policies flexibly. The most important application of the proposal is to provide inverter-based power systems with a mechanism to fully explode the capacities of the power converter in a safe way during unbalanced grid voltages. The importance of this flexible operation is the wide range of possible strategies that could be developed in a compact solution.

The main advantage of this reference generator is its fully flexible operation, capable to balance the amounts of positive and negative active and reactive power at the same time while keeping the injected current safely controlled to a predefined maximum value. This flexibility allows to define the behaviour of the system in different scenarios, to increase the system efficiency and the inmunity against voltage sags, or to better support the grid voltage by improving the voltage profile at the PCC, and therefore, contributing to avoid sudden tripping and cascade disconnection. Otherwise, the main disadvantage of the proposed reference generator is the complexity of the control compared with conventional schemes. Even if the complexity of the algorithm seems high, the computacional overhead of the reference generator is low for the embedded architecture, and supposes less than $7 \%$ of the total time required for the whole control algorithm.

It should be mentioned that the strategies can be on-line switched as required, since the computation of the power references is done based on PCC grid voltages. Then, only a fast sequence extractor is needed to implement the proposed reference generator. Also, the experimental tests have shown good dynamics even for voltage step changes during the sag which can emulate the behaviour of grid faults in weak grids.

\section{E. Discussion on the selection of $k_{p}$ and $k_{q}$ values}

Once the advantages, disadvantages and applications have been discussed, the selection of the parameters of the reference generator is discussed. When a sag perturbs the grid, one of the main questions is to decide how the inverter should behave during the fault. The behaviour of the power source during grid faults is an open research topic. Therefore, the main objective of the proposed reference generator is to contribute with a flexible control scheme capable to safely inject the maximum rated current of the inverter and improve the power capacities during contingencies. The decission on which strategy is the best for a given scenario is difficult to attain. The answer to this problem depends on many aspects: the grid impedance, the rated power, and the type of grid fault, among others. All these parameters should be analyzed to design the values of $k_{p}$ and $k_{q}$ that will result in an improved ride-through strategy. In the following, three scenarios are analyzed to discuss the posible strategies.

The first scenario deals with a voltage sag in a stiff grid with a DG source with small contribution to the total power of the grid. In such a case, no voltage support control can be obtained since the reactive power will produce small effects on the voltage at the PCC, and some strategies as the phase power equalization can be well suited for local loads as stated previously.

The second scenario presents a voltage sag in a grid with high resistive behaviour. Under these considerations, to improve the voltage profile at the PCC, positive and negative active powers are required. Therefore, grid operators can 
define smart control objectives by setting the values of $k_{p}$ accordingly.

The third scenario is similar to previous one although the grid is mainly inductive and weak, and a high rated DG power source is considered. Opposite to previous scenario, the selection of $k_{q}$ will have a great impact on the voltage profile at the PCC. Then, voltage support services can be better obtained with this strategy, specially if the plant has a great contribution to the total power of the grid [17].

Since the mainly resistive or mainly inductive scenarios does not hold for all DG power plants, the affectation of the proposed reference generator on the grid voltage can be obtained from the following expressions [34] (see Fig. 1 for details).

$$
\begin{aligned}
& V_{g}^{+}=\sqrt{\left(V^{+}-\omega L I_{q}^{+}-R I_{p}^{+}\right)^{2}+\left(\omega L I_{p}^{+}-R I_{q}^{+}\right)^{2}} \\
& V_{g}^{-}=\sqrt{\left(V^{-}+\omega L I_{q}^{-}-R I_{p}^{-}\right)^{2}+\left(\omega L I_{p}^{-}+R I_{q}^{-}\right)^{2}} .
\end{aligned}
$$

As can be shown from (70)-(71), and (40)-(43), the best decision on the selection of $k_{p}$ and $k_{q}$ is difficult to attain, although grid operators can define some basic rules that will contribute with better strategies during grid faults. For three phase voltage sags, $k_{p}$ and $k_{q}$ will be near 1 since only positive sequence voltage should be increased. For one- or twophase voltage sags, a balance between positive and negative sequences should be considered to mitigate undervoltage in the faulty phase(s) and to avoid overvoltage in the non-faulty phase(s). In mainly inductive grids, $k_{q}$ will have more impact on the PCC voltage, while in resistive grids, $k_{p}$ will produce higher voltage variations as stated previously.

\section{CONCLUSIONS}

This paper has presented a reference generator for threephase grid-connected inverters operating under unbalanced voltage sags. Two control objectives are simultaneously accomplished: to control the amplitude of the injected currents, and to exploit the power capacity of the inverter. Therefore, DG power plants can avoid overcurrent tripping while flexibly helping to mitigate the adverse effects of grid faults.

The main contribution of this work is the development of a reference generator either for active or reactive power for any given unbalanced voltage sag. The control proposal is capable to balance the amount of positive and negative sequence powers by setting two control parameters. Also, a novel ridethrough strategy has been developed as a second significant contribution of this paper to show the flexible behaviour of the main proposal.

The mathematical formulation proposed in this work ensures that i) the phase currents are controlled within safety limits, ii) the algorithm is fully flexible to set the positive and negative active and reactive power references and iii) the selection of the control strategy can improve voltage ridethrough services.

The proposed reference generator had shown a fairly good dynamic behavior for time-varying complex voltage sags as presented in the above set of experiments. Several control strategies have been developed in order to cope with different requirements.

With the proposed reference generator, the grid operators can prioritize supporting or feeding the grid, while can also define smart values for the control gains $k_{p}$ and $k_{q}$ that help to regulate the phase voltages at the $\mathrm{PCC}$ or to derive ridethrough strategies. The selection of these values is an open research topic. Further work should be developed to help the grid operators in the definition of operational strategies during severe perturbations and different grid scenarios.

\section{REFERENCES}

[1] S. Martin-Martinez, E. Gomez-Lazaro, A. Molina-Garcia, A. ViguerasRodriguez, M. Milligan, and E. Muljadi, "Participation of wind power plants in the spanish power system during events," in 2012 IEEE Power and Energy Society General Meeting, 2012, pp. 1-8.

[2] Offprint of the Operation Procedure O.P. 12.2: Technical requirements for wind power and photovoltaic installations and any generating facilities whose technology does not consist on a synchronous generator directly connected to the grid., Asociación Empresarial Eólica, Oct. 2008, [Online]. Available: www.aeeolica.org.

[3] M. Altin, O. Goksu, R. Teodorescu, P. Rodriguez, B.-B. Jensen, and L. Helle, "Overview of recent grid codes for wind power integration," in 12th Int. Conf. on Optimization of Electrical and Electronic Equipment, May 2010, pp. 1152-1160.

[4] A. Vidal, F. Freijedo, A. Yepes, P. Fernandez-Comesana, J. Malvar, O. Lopez, and J. Doval-Gandoy, "Assessment and optimization of the transient response of proportional-resonant current controllers for distributed power generation systems," IEEE Trans. Ind. Electron., vol. 60, no. 4, pp. 1367-1383, 2013.

[5] A. Yepes, A. Vidal, O. Lopez, and J. Doval-Gandoy, "Evaluation of techniques for cross-coupling decoupling between orthogonal axes in double synchronous reference frame current control," IEEE Trans. Ind. Electron., vol. 61, no. 7, pp. 3527-3531, July 2014.

[6] F. Wang, J. L. Duarte, and M. A. M. Hendrix, "Pliant active and reactive power control for grid-interactive converters under unbalanced voltage dips," IEEE Trans. Power Electron., vol. 26, no. 5, pp. 1511-1521, May 2011.

[7] S. Alepuz, S. Busquets-Monge, J. Bordonau, J. Martinez-Velasco, C. Silva, J. Pont, and J. Rodriguez, "Control strategies based on symmetrical components for grid-connected converters under voltage dips," IEEE Trans. Ind. Electron., vol. 56, no. 6, pp. 2162-2173, Jun. 2009.

[8] A. Camacho, M. Castilla, J. Miret, J. Vasquez, and E. Alarcón-Gallo, "Flexible voltage support control for three phase distributed generation inverters under grid fault," IEEE Trans. Ind. Electron., vol. 60, no. 4, pp. 1429-1441, 2013.

[9] L. Xu and Y. Wang, "Dynamic modeling and control of DFIG-based wind turbines under unbalanced network conditions," IEEE Trans. Power Syst., vol. 22, no. 1, pp. 314-323, 2007.

[10] S. Chaudhary, R. Teodorescu, P. Rodriguez, P. Kjaer, and A. Gole, "Negative sequence current control in wind power plants with VSCHVDC connection," IEEE Trans. Sustainable Energy, vol. 3, no. 3, pp. 535-544, Jul. 2012.

[11] H.-S. Song and K. Nam, "Dual current control scheme for PWM converter under unbalanced input voltage conditions," IEEE Trans. Ind. Electron., vol. 46, no. 5, pp. 953-959, Oct. 1999.

[12] T. Lee, S. Hu, and Y. Chan, "D-STATCOM with positive-sequence admittance and negative-sequence conductance to mitigate voltage fluctuations in high-level penetration of distributed generation systems," IEEE Trans. Ind. Electron., vol. 60, no. 4, pp. 1417-1428, Apr. 2013.

[13] J. Miret, M. Castilla, A. Camacho, L. García de Vicua, and J. Matas, "Control scheme for photovoltaic three-phase inverters to minimize peak currents during unbalanced grid-voltage sags," IEEE Trans. Power Electron., vol. 27, no. 10, pp. 4262-4271, 2012.

[14] P. Rodriguez, A. Luna, J. Hermoso, I. Etxeberria-Otadui, R. Teodorescu, and F. Blaabjerg, "Current control method for distributed generation power generation plants under grid fault conditions," in 37th Ann. Conf. on IEEE Ind. Electron. Society (IECON), Nov. 2011, pp. 1262-1269.

[15] P. Rodriguez, G. Medeiros, A. Luna, M. Cavalcanti, and R. Teodorescu, "Safe current injection strategies for a statcom under asymmetrical grid faults," in IEEE Energy Conversion Congr. and Expo. (ECCE), Sep. 2010, pp. 3929-3935. 
[16] M. Castilla, J. Miret, A. Camacho, J. Matas, and L. García de Vicuña, "Voltage support control strategies for static synchronous compensators under unbalanced voltage sags," IEEE Trans. Ind. Electron., vol. 61, no. 2, pp. 808-820, 2014

[17] A. Camacho, M. Castilla, J. Miret, R. Guzman, and A. Borrell, "Reactive power control for distributed generation power plants to comply with voltage limits during grid faults," IEEE Trans. Power Electron., vol. 29 no. 11, pp. 6224-6234, Nov. 2014

[18] J. Suul, A. Luna, P. Rodriguez, and T. Undeland, "Virtual-flux-based voltage-sensor-less power control for unbalanced grid conditions," IEEE Trans. Power Electron., vol. 27, no. 9, pp. 4071-4087, 2012.

[19] C.-T. Lee, C.-W. Hsu, and P.-T. Cheng, "A low-voltage ride-through technique for grid-connected converters of distributed energy resources," IEEE Trans. Ind. Appl., vol. 47, no. 4, pp. 1821-1832, Jul. 2011.

[20] K. Ma and F. Blaabjerg, "Thermal optimised modulation methods of three-level neutral-point-clamped inverter for $10 \mathrm{MW}$ wind turbines under low-voltage ride through," IET Power Electron., vol. 5, no. 6, pp. 920-927, Jul. 2012.

[21] F. Blaabjerg, R. Teodorescu, M. Liserre, and A. Timbus, "Overview of control and grid synchronization for distributed power generation systems," IEEE Trans. Ind. Electron., vol. 53, no. 5, pp. 1398-1409, Oct. 2006.

[22] P. Rodriguez, J. Pou, J. Bergas, J. I. Candela, R. P. Burgos, and D. Boroyevich, "Decoupled double synchronous reference frame PLL for power converters controls," IEEE Trans. Power Electron., vol. 22, no. 2, pp. 584-592, Mar. 2007.

[23] F. Rodriguez, E. Bueno, M. Aredes, L. Rolim, F. Neves, and M. Cavalcanti, "Discrete-time implementation of second order generalized integrators for grid converters," in 34th Annu. Conf. of IEEE Ind. Electron., Nov. 2008, pp. 176-181.

[24] J. Matas, M. Castilla, J. Miret, L. García de Vicuña, and R. Guzman, "An adaptive pre-filtering method to improve the speed/accuracy trade-off of voltage sequence detection methods under adverse grid conditions," IEEE Trans. Ind. Electron., vol. 61, no. 5, pp. 2139-2151, 2014

[25] F. Neves, H. Souza, E. Bueno, M. Rizo, F. Bradaschia, and M. Cavalcanti, "A space-vector discrete fourier transform for detecting harmonic sequence components of three-phase signals," in 35th Annu. Conf. of IEEE Ind. Electron., Nov. 2009, pp. 3631-3636.

[26] P. Rodriguez, A. Luna, I. Candela, R. Mujal, R. Teodorescu, and F. Blaabjerg, "Multiresonant frequency-locked loop for grid synchronization of power converters under distorted grid conditions," IEEE Trans. Ind. Electron., vol. 58, no. 1, pp. 127-138, Jan. 2011.

[27] P. Roncero-Sánchez, X. del Toro García, A. Parreno Torres, and V. Feliu, "Fundamental positive- and negative-sequence estimator for grid synchronization under highly disturbed operating conditions," IEEE Trans. Power Electron., vol. 28, no. 8, pp. 3733-3746, Aug. 2013.

[28] W. Li, X. Ruan, C. Bao, D. Pan, and X. Wang, "Grid synchronization systems of three-phase grid-connected power converters: A complexvector-filter perspective," IEEE Trans. Ind. Electron., vol. 61, no. 4, pp. 1855-1870, April 2014.

[29] S. Vazquez, J. Sanchez, M. Reyes, J. Leon, and J. Carrasco, “Adaptive vectorial filter for grid synchronization of power converters under unbalanced and/or distorted grid conditions," IEEE Trans. Ind. Electron., vol. 61, no. 3, pp. 1355-1367, March 2014.

[30] A. Yazdani and R. Iravani, Voltage-Sourced Converters in Power Systems. New Jersey, USA: Wiley, 2010.

[31] "IEEE recommended practice for electric power distribution for industrial plants," IEEE Std 141-1993, pp. 1-768, Apr. 1994.

[32] S. Cundeva, R. Neumann, M. Bollen, Z. Kokolanski, J. Vuletic, A. Krkoleva, S. Djokic, K. van Reusel, and K. Stockman, "Immunity against voltage dips-Main recommendations to stakeholders of the CIGRE/CIRED/UIE Joint Working Group C4.110," Int. J. Emerg. Sci, vol. 1, no. 4, pp. 555-563, Dec. 2011.

[33] "IEEE draft. Recommended practice for voltage sag and interruption ride-through testing for end use electrical equipment less than 1,000 volts," IEEE P1668/D3Q, pp. 1-87, Apr. 2013.

[34] A. Camacho, M. Castilla, J. Miret, J. Matas, R. Guzman, O. de SousaPerez, P. Marti, and L. Garcia de Vicuna, "Control strategies based on effective power factor for distributed generation power plants during unbalanced grid voltage," in 39th Ann. Conf. on IEEE Ind. Electron. Society (IECON), Nov 2013, pp. 7134-7139.

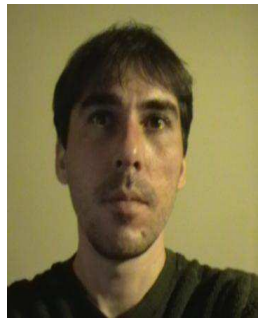

Antonio Camacho received the B.S. degree in chemical engineering and the M.S. degree in automation and industrial electronics from the Technical University of Catalonia, Barcelona, Spain, in 2000 and 2009, respectively.

Currently, he is pursuing the Ph.D. degree in electronic engineering also at the Technical University of Catalonia. His research interests include networked and embedded control systems, industrial informatics, and power electronics.

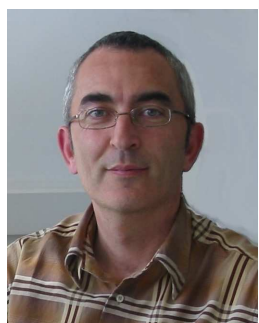

Miguel Castilla received the B.S., M.S. and Ph.D. degrees in telecommunication engineering from the Technical University of Catalonia, Barcelona, Spain, in 1988, 1995, and 1998, respectively.

Since 2002, he has been an Associate Professor in the Department of Electronic Engineering, Technical University of Catalonia, where he teaches courses on analog circuits and power electronics. His research interests are in the areas of power electronics, nonlinear control, and renewable energy systems.

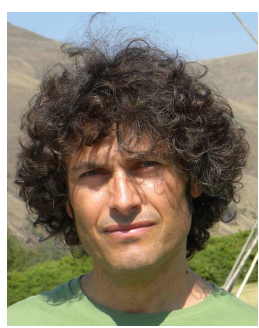

Jaume Miret (M'98) received the B.S. degree in telecommunications and the M.S. and Ph.D. degrees in electronics from the Technical University of Catalonia, Barcelona, Spain, in 1992, 1999, and 2005 respectively.

$\mathrm{He}$ is currently an Associate Professor with the Department of Electronic Engineering, Technical University of Catalonia, Vilanova i la Geltrú, Spain, where he teaches courses on digital design and circuit theory. His research interests include dc-ac converters, active power filters, and digital control.

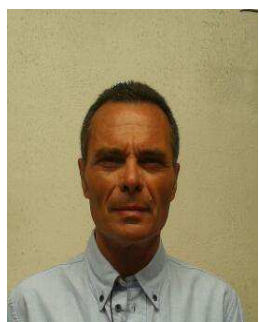

Angel Borrell received the B.S. degree in electrical engineering, M.S. degree in automation and industrial electronics engineering and $\mathrm{PhD}$ in electronics engineering from the Technical University of Catalonia, Barcelona, Spain, in 1993, 2006 and 2012 respectively.

Since 1994, he has been an Associate Professor in the Department of Electrical Engineering, Escola Universitària Salesiana de Sarrià, where he teaches courses on electrical machines and automation. His research interest are in the areas of power electronics, electric motor drives and renewable energy systems.

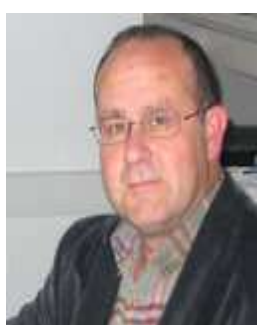

Luis García de Vicuña received the Ingeniero de Telecomunicación and Dr.Ing. degrees from the Technical University of Catalonia, Barcelona, Spain, in 1980 and 1990, respectively, and the Dr.Sci. degree from the Université Paul Sabatier, Toulouse, France, in 1992.

From 1980 to 1982, he was an Engineer with Control Applications Company. He is currently a Professor in the Department of Electronic Engineering, Technical University of Catalonia, where he teaches courses on power electronics. His research interests include power electronics modeling, simulation and control, active power filtering, and high-power-factor ac/dc conversion. 